\title{
Electrochemical Wire in Binuclear Ruthenium Complexes
}

\author{
Yoshimasa HOSHINO*, Tadakatsu NISHIKAWA, Kazushige TAKAHASHI \\ and Koichi AOKI
}

Received February 10, 1993 ; Accepted March 23, 1993

\section{INTRODUCTION}

Acetylene linkers are very attractive connection as a molecular wire. Recently, a series of donor-acceptor acetylene linker compounds were prepared and their second-order molecular hyperpolarizabilities were investigated1). We also synthesized binuclear complexes including two redox active sites bridged by two acetylene linkers and studied their electrochemical properties2). In the binuclear complex including two $\operatorname{tris}(\beta$-diketonato)ruthenium(III) moieties the interactions between $\mathrm{Ru}^{\mathrm{III}}$ and $\mathrm{Ru}$ II are very weak, while those between $\mathrm{Ru}^{\mathrm{IV}}$ and $\mathrm{Ru} \mathrm{III}$ are relatively strong. This fact suggests that the acetylene linkers in the $\mathrm{Ru}^{\mathrm{IV}}$ - $\mathrm{Ru}$ III state act as a molecular wire ${ }^{2)}$. In other words, acetylene linkers have propagative function of energy depending on the orbital energy level of the metals. We call the molecular wires with the potential dependence 'electrochemical wire'.

We report electrochemical characteristics of new binuclear $\quad \beta$-diketonatoruthenium(III) complexes bridged by three and four acetylene linkers in some nonaqueous solvents. Dependence of the propagative function on the number of the acetylene linkers is briefly discussed.

\section{EXPERIMENTAL}

( $\mu-1,1,6,6-$ Tetraacetyl-2,4-hexadiynato)bis[bis(2, 2,6,6-tetramethyl-3,5-heptanedionato)ruthenium(III)] (Ru2Ru) was prepared as reported previously2), and ( $\mu$-1,1,8,8-tetraacetyl-2,4,6-octatriynato)bis[bis(2, \footnotetext{
Department of Applied Physics, Faculty of Engineering, (Fukui University, 9-1, Bunkyo 3-chome, Fukuishi 910, Japan)

Key Words : Molecular Wire, Acetylene Linkers, Binuclear Ruthenium Complexes, Comproportionation Constants
}

2,6,6-tetramethyl-3,5-heptanedionato)ruthenium(III)] (Ru3Ru) and ( $\mu-1,1,10,10$-tetraacetyl-2,4,6,8decatetraynato)bis[bis(2,2,6,6-tetramethyl-3,5-heptanedionato)ruthenium(III)] (Ru4Ru) were synthesized as described elsewhere ${ }^{3)}$. Structures of these complexes are shown in Fig. 1. Voltammograms of the complexes were recorded as described elsewhere4). Acetonitrile, dichloromethane, butyronitrile, nitromethane, or benzonitrile containing $0.1 \mathrm{~mol} \mathrm{dm}^{-3}$ tetrabutylammonium tetrafluoroborate $\left(\mathrm{TBABF}_{4}\right)$ was used as a base solution. The test electrode was a stationary platinum disk $(\phi=0.2 \mathrm{~mm})$. Potentials were measured against an $\mathrm{Ag} \mid \mathrm{AgCl}, \mathrm{KCl}$ (saturated aqueous) at $25^{\circ} \mathrm{C}$. The ferrocenium/ferrocene potentials were adopted as an internal reference potential.

\section{RESULTS AND DISCUSSION}

Complexes Ru3Ru and Ru4Ru showed two pairs of peaks in the dichloromethane, one having a shoulder on the positive side of the triangular-wave voltammograms and the other being broad peaks on the negative side. These peak potentials were independent of the sweep rate, suggesting that each step was nernstian. Both the anodic waves correspond to two consecutive, nernstian one-electron oxidation steps and the cathodic waves attribute to doubly overlapping reduction processes. The half-wave potentials $\left(E_{1 / 2}\right)$

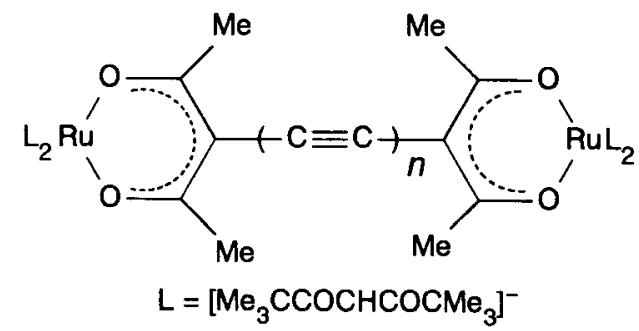

Fig. 1. Binuclear ruthenium(III) complexes bridged by acetylene linkers. $n=2$, Ru2Ru; 3, Ru3Ru; 4, Ru4Ru. 
were determined by differential pulse voltammograms (DPV) and some $E_{1 / 2}$ 's were estimated from the peak half-width in the DPV with use of the technique in ref. 5.

The equilibrium constants $\left(K_{\mathrm{c}}\right)$ for the comproportionation reaction are defined as

$K_{\mathrm{c}}(\mathrm{Z}, \mathrm{Z}-\mathrm{I})=\left[\mathrm{Ru}^{\mathrm{Z}}-\mathrm{Ru} \mathrm{Z}^{\mathrm{I}}\right]^{2} /[\mathrm{Ru} \mathrm{Z}-\mathrm{Ru} \mathrm{Z}][\mathrm{Ru} \mathrm{Z}-\mathrm{I}-\mathrm{Ru} \mathrm{Z}-\mathrm{I}]$

$K_{\mathrm{c}}=\exp \left[\Delta E_{1 / 2} F / R T\right]$

where $\Delta E_{1 / 2}=\left|E_{1 / 2}(1)-E_{1 / 2}(2)\right|$. The $\Delta E_{1 / 2}$ and the $K_{\mathrm{c}}\left(\right.$ at $25^{\circ} \mathrm{C}$ ) are presented in Table 1 together with the estimated metal-metal distance $\left(d_{\mathrm{M}-\mathrm{M}}\right)$.

The $\log K_{c}(I V, I I I)$ for $R u 3 R u$ is close to two, indicating that two Ru metals strongly interact through acetylene linkers in spite of the long $d_{\mathbf{M}-\mathbf{M}}$. Both the $K_{\mathrm{c}}(\mathrm{IV}, \mathrm{III})$ and the $K_{\mathrm{c}}(\mathrm{III}, \mathrm{II})$ are not very dependent on the solvents, except for the $K_{c}(I V, I I I)$ in dichloromethane. However, the $K_{\mathrm{c}}(\mathrm{IV}, \mathrm{III})$ values depend on the $d_{\mathrm{M}-\mathrm{M}}$ or the number of acetylene linkers $(n)$. Plots of the $\log K_{\mathrm{c}}$ vs the reciprocal of the $d_{\mathrm{M}-\mathrm{M}}$ and the reciprocal of $n$ give two straight lines (in Fig. 2). Linearity of the relationship between the $\log K_{\mathrm{c}}$ and the $n(r=1.00)$ is better than that of the relationship between the $\log K_{\mathrm{c}}$ and the $d_{\mathrm{M}-\mathrm{M}}(\mathrm{r}=0.98)$. These facts indicate that the interaction between $\mathrm{Ru}^{\mathrm{IV}}$ and
$\mathrm{Ru}^{\mathrm{III}}$ is not dominated by the electrostatic fields but is by the electronic coupling through the acetylene linkers. This interaction appears to occur by accessing the $\mathrm{d} \pi$ orbital energy level for $\mathrm{Ru}^{\mathrm{IV}}$ to $\mathrm{p} \pi$ energy levels of acetylene linkers. Thus, we can control the interaction between two redox sites by means of operating the potential of the sites. The acetylene linkers are just electrochemical wires which can work as a switching device.

The present work was partially supported by The Japan Securities Scholarship Foundation.

\section{REFERENCES}

1) A. E. Stiegman, E. Graham, K. J. Perry, L. R. Khundkar, L.-T. Cheng and J. W. Perry, J. Am. Chem. Soc, 113, 7658 (1991).

2) Y. Kasahara, Y. Hoshino, M. Kajitani, K. Shimizu and G. P. Satô, Organometallics, 11, 1968 (1992).

3) Y. Hoshino, T. Nishikawa, K. Takahashi and K. Aoki in preparation to be submitted.

4) K. Aoki, T. Aramoto and Y. Hoshino, J. Electroanal. Chem., Interfacial Electrochem., 340, 127 (1992).

5) D. E. Richardson and H. Taube, Inorg. Chem., 20, 1278 (1981).

Table 1. Difference between Reversible Half-Wave Potentials $\left(\Delta E_{1 / 2}\right)$ and Comproportionation Constants $\left(K_{\mathrm{c}}\right)$ in Nonaqueous Media with Dielectric Constants $\left(D_{\mathrm{c}}\right)$ and Estimated Metal-Metal Distances $\left(d_{\mathrm{M}-\mathrm{M}}\right)$ of the Binuclear Ruthenium Complexes

\begin{tabular}{|c|c|c|c|c|c|c|c|}
\hline \multirow[t]{2}{*}{ Complex } & \multirow[t]{2}{*}{ Solvent } & \multirow[t]{2}{*}{$D_{\mathrm{c}}$} & \multicolumn{2}{|c|}{$\mathbf{R u} I V / R u^{I I I}$} & \multicolumn{2}{|c|}{$\mathrm{Ru}^{\mathrm{III}} / \mathbf{R} \mathbf{u}^{\mathrm{II}}$} & \multirow{2}{*}{$d_{\mathrm{M}-\mathrm{M}^{\mathrm{nm}}}$} \\
\hline & & & $\Delta E_{1 / 2} / \mathrm{mV}$ & $\left.\log K_{c}^{a}\right)$ & $\Delta E_{1 / 2} / \mathrm{m}$ & $\left.\log K_{\mathrm{c}} \mathrm{a}\right)$ & \\
\hline \multirow[t]{3}{*}{ Ru2Ru } & $\mathrm{CH}_{2} \mathrm{Cl}_{2}$ & 7.8 & 225 & 3.8 & 111 & 1.9 & 1.31 \\
\hline & $\mathrm{BuCN}$ & 20.3 & 169 & 2.9 & $92^{b)}$ & 1.6 & \\
\hline & $\mathrm{C}_{6} \mathrm{H}_{5} \mathrm{CN}$ & 25.2 & 183 & & $86^{\text {b) }}$ & 1.5 & \\
\hline \multirow[t]{3}{*}{ Ru3Ru } & $\mathrm{CH}_{2} \mathrm{Cl}_{2}$ & 7.8 & 124 & 2.1 & 53 & 0.9 & 1.56 \\
\hline & $\mathrm{BuCN}$ & 20.3 & 99 & 1.7 & $78 b)$ & 1.3 & \\
\hline & $\mathrm{C}_{6} \mathrm{H}_{5} \mathrm{CN}$ & 25.2 & 117 & 2.0 & $74^{b)}$ & 1.3 & \\
\hline \multirow[t]{5}{*}{ Ru4Ru } & $\mathrm{CH}_{2} \mathrm{Cl}_{2}$ & 7.8 & 86 & 1.5 & 55 & 0.9 & 1.82 \\
\hline & $\mathrm{BuCN}$ & 20.3 & 78 & 1.3 & $60^{b)}$ & 1.0 & \\
\hline & $\mathrm{C}_{6} \mathrm{H}_{5} \mathrm{CN}$ & 25.2 & 76 & 1.3 & $63^{b)}$ & 1.1 & \\
\hline & $\mathrm{CH}_{3} \mathrm{NO}_{2}$ & 35.9 & 60 & 1.0 & 50 & 0.8 & \\
\hline & $\mathrm{CH}_{3} \mathrm{CN}$ & 37.5 & 60 & 1.0 & $58^{b)}$ & 1.0 & \\
\hline
\end{tabular}

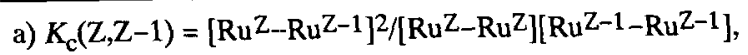
$K_{\mathrm{c}}=\exp \left[\Delta E_{1 / 2} F / R T\right]$.

b) Quasi-nernstian process.

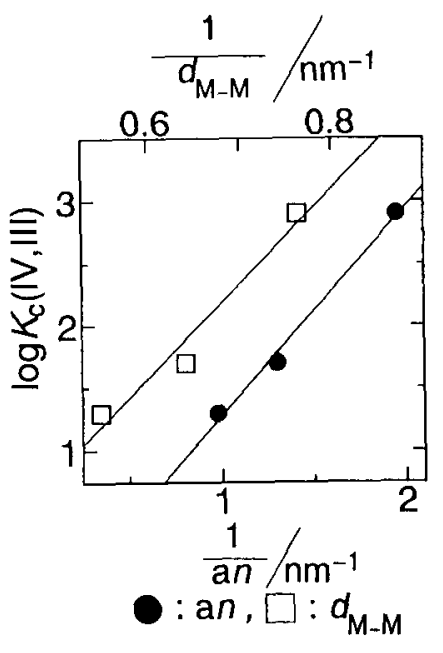

Fig. 2. Plots of $\log K_{\mathrm{c}}$ (in $\mathrm{BuCN}$ ) vs. the reciprocal of the $d_{M-M}$ and the reciprocal of $n$, where a $(=0.256 \mathrm{~nm})$ is length per one acetylene linker. 